\title{
Assessing the punch-through hazard of a spudcan on sand overlying clay
}

\author{
P. HU*, D. WANG*, S. A. STANIER* and M. J. CASSIDY*
}

\begin{abstract}
A complete analytical method to describe the full load-penetration resistance profile of a mobile jackup spudcan footing penetrating a sand over clay stratigraphy is described. It is based on both large deformation finite-element analyses and geotechnical centrifuge experiments. The coupled EulerianLagrangian (CEL) approach is used to accommodate the large deformations of a spudcan footing penetrating sand overlying clay. Modified Mohr-Coulomb and Tresca models describe the sand and clay behaviour, with modifications accounting for the effects of strain softening on the response of the soil. The CEL results are shown to match centrifuge tests well, allowing the numerical study to be extended parametrically, and with confidence, to cover the range of layer geometries, sand relative densities and footing shapes that are of practical interest to offshore jack-ups. The results are used to (a) assess the performance of an existing model to predict the peak resistance in the sand layer (extending its range of application to medium dense to dense sands and to conical footings of angle $0^{\circ}$ to $21^{\circ}$ ), and (b) develop an expression for the bearing capacity factor when the footing penetrates into the underlying clay. Using the analytical formulas proposed, retrospective simulations of centrifuge tests show that the method provides a reasonable estimate of the peak punch-through load, the behaviour in the underlying clay, as well as the punch-through distance; the latter being a basic reflection of the severity of a potential punch-through failure.
\end{abstract}

KEYWORDS: bearing capacity; centrifuge modelling; clays; finite-element modelling; offshore engineering; sands

\section{INTRODUCTION}

Jack-up platforms are self-elevating mobile rigs, commonly employed to perform offshore oil and gas drilling. The advantage of their mobility has led to their use in a wide range of geographic and geotechnical conditions. Upon arrival at a new site, the footings of the jack-up platforms, known as spudcans, are preloaded to a vertical load that exceeds the maximum in-service load by using the weight of the rig and seawater ballast tanks. This serves as a proof of competence for resisting potential storm loads during operation (and has additional benefits such as possible hardening of clayey soil and of pushing the spudcan sufficiently into the seabed so that the potential problems associated with scour are minimised, as discussed further by Osborne et al. (2011)). However, in a seabed consisting of sand overlying clay, there is a potential for punch-through failure to occur during the installation. This is characterised by a rapid spudcan penetration of several metres in a few seconds (McClelland et al., 1981; Brennan et al., 2006; Kostelnik et al., 2007; Dean, 2010). Such a failure may lead to damage or loss of the jack-up rig.

With punch-through being recognised as one of the most common hazards during spudcan installation and operation (Osborne \& Paisley, 2002), there is a need to improve the design approach for soil conditions liable to punch-through and to predict the severity of such an event. The punchthrough distance (from onset of punch-through failure until equilibrium is re-established) of a punch-through event can be used as a basic indicator of severity and it can be characterised by two key phases: $(a)$ the magnitude and depth

Manuscript received 2 June 2014; revised manuscript accepted 3 June 2015. Published online ahead of print 11 August 2015.

Discussion on this paper closes on 1 April 2016, for further details see p. ii.

*Centre for Offshore Foundation Systems and ARC Centre of Excellence for Geotechnical Science and Engineering, The University of Western Australia, Crawley, Australia. of peak resistance in the sand layer and $(b)$ the depth at which the resistance in the underlying clay layer becomes equal to the peak resistance.

Several conceptual models (Hanna \& Meyerhof, 1980; Okamura et al., 1998; Teh, 2007; Lee et al., 2013b; Hu et al., 2014a) have been developed to estimate the peak resistance, $q_{\text {peak }}$ (in $\mathrm{kPa}$ ), that occurs in the sand layer. The most accurate of these models (according to comparisons of the predictions to several series of centrifuge tests with medium dense to dense sand overlying clay) is the model of $\mathrm{Hu}$ et al. (2014a). This model is based on the failure-stress-dependent model of Lee et al. (2013b), refined and extended to account for mobilisation depth. Confirming the observations of Teh et al. (2010), the depth at which the peak resistance is mobilised was found experimentally to be $\sim 0 \cdot 12 H_{\mathrm{s}}$ on average, where $H_{\mathrm{s}}$ is the sand layer thickness. The performance of this model for medium dense sands has been supported numerically by the large deformation finite-element (FE) analyses of Hu et al. (2014b); however, its performance for dense sands is yet to be validated numerically.

The equation for $q_{\text {peak }}$ in $\mathrm{Hu}$ et al. (2014a) is limited to values of $q_{\text {peak }}$ lower than the bearing capacity of the spudcan foundation in the sand alone, with methods for calculating the bearing capacity of circular footings in a pure sand layer described in, among others, Brinch Hansen (1970), Cassidy \& Houlsby (1999, 2002), Randolph et al. (2004) and Lee (2009). In the design of the experimental programmes of Lee et al. (2013a), $\mathrm{Hu}$ et al. (2014a) and $\mathrm{Hu}$ (2015), this limited the ratio of sand thickness $H_{\mathrm{s}}$ to the spudcan diameter $D$ to less than 1. For higher ratios spudcans would remain in the sand layer under pressures typically experienced during jack-up preload (see discussion in Lee et al. (2013a)). Therefore, the model of this paper is limited to the testing programme used in its calibration, with $H_{\mathrm{s}} / D \leq 1$.

When the spudcan penetrates through the sand layer into the clay layer, a sand plug is trapped underneath the spudcan (see Fig. 1), effectively enlarging the footing size and mobilising clay with higher undrained shear strength under 


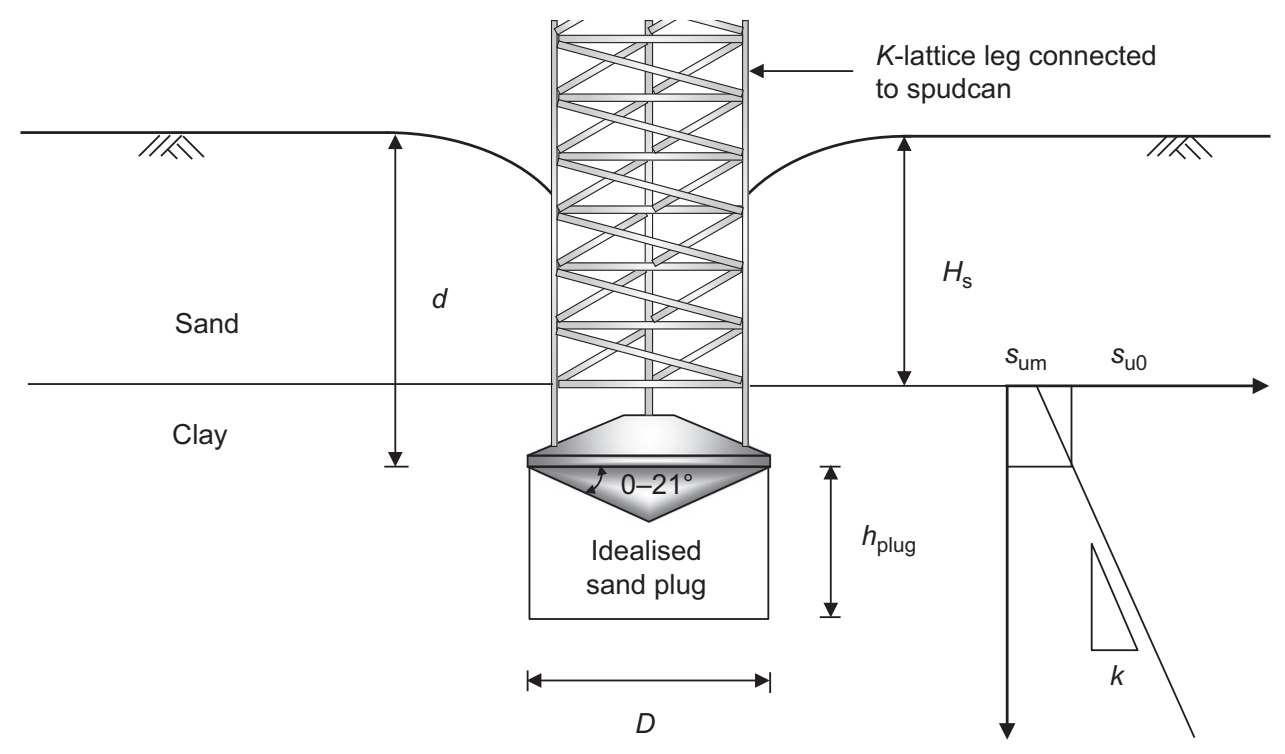

Fig. 1. Schematic diagram of spudcan foundation penetration in sand overlying clay

the base of the sand plug. The bearing capacity (at the spudcan depth) in the underlying clay can be expressed as

$$
q_{\text {clay }}=N_{\mathrm{c}} s_{\mathrm{u} 0}+h_{\text {plug }} \gamma_{\mathrm{c}}^{\prime}
$$

where $N_{\mathrm{c}}$ is the bearing capacity factor in the clay layer (expressed in terms of the widest cross-sectional area of the footing and directly incorporating traditional shape and depth factors, following discussions by Randolph et al., 2004); $s_{\mathrm{u} 0}$ is the soil strength at the lowest elevation of the spudcan widest cross-sectional area; $h_{\text {plug }}$ is the sand plug height, approximated as $0 \cdot 9 H_{\mathrm{s}}$ (Teh, 2007; Hu et al., 2014b); and $\gamma_{c}^{\prime}$ is the effective unit weight of the clay. The first term is the bearing capacity for a weightless soil, while the second term accounts for the effective weight of the clay replaced by the trapped sand.

The $N_{\mathrm{c}}$ depends on the evolution of the sand plug geometry and classical expressions of $N_{\mathrm{c}}$ for a single clay layer (Houlsby \& Martin, 2003; Hossain et al., 2006) cannot consider the sand plug effect when predicting the penetration resistance of a spudcan following punch-through on sand overlying clay. Current ISO (2012) guidelines refer to the full profile prediction method in Teh (2007), for which the equation proposed by Hossain et al. (2006) is used to provide the $N_{\mathrm{c}}$ values. This equation ignores the contribution of the sand plug, which increases the penetration resistance due to additional clay being sheared around the periphery of the sand plug and also due to the higher clay strength being mobilised at the bottom of the sand plug, as confirmed from observations in clay underlying sand layer using particle image velocimetry (PIV) analysis (Teh et al., 2008; $\mathrm{Hu}$, 2015).

Through wished-in-place analyses using the small strain FE method, Lee (2009) proposed two equations to estimate $N_{\text {c }}$ corresponding to shallow and deep failure mechanisms (see Table 1). The sand plug height is a key input for these equations since the resistance in the clay is taken as a function of the clay strength at the base of the sand plug. However, there was insufficient experimental or numerical evidence to confirm an appropriate height for the sand plug. As a result, a range of $0 \cdot 6-0 \cdot 9 H_{\mathrm{s}}$, was used by Lee (2009) to give lower and upper bound estimates on the penetration resistance. This rather wide range of sand plug height limits the accuracy of the full penetration resistance profiles predicted and the estimations of the potential punch-through distance. Lee et al. (2013a) suggested a linearly increasing $N_{\mathrm{c}}$ with $H_{\mathrm{s}} / D$, rather than sand plug height, from a series of dense sand centrifuge tests on flat and spudcan footings. This relationship was improved by numerical and experimental studies incorporating both loose and medium dense sands overlying clay of varying strength in $\mathrm{Hu}$ et al. (2014b). Although the clay beneath and around the sand plug is partially disturbed, the intact undrained strength of the clay at the widest cross-section of the footing is used to estimate the resistance in the clay layer, since this is representative of the information that would typically be available from a site investigation. The effect of soil disturbance in the clay layer is essentially considered when fitting the expression of $N_{\mathrm{c}}$. However, the values for $N_{\mathrm{c}}$ were derived for a particular spudcan shape with a typical $13^{\circ}$ conical underside angle. The effect of footing shape combined with the relative density of the sand and shear strength of the clay was not considered in Hu et al. (2014b).

\section{NUMERICAL METHODOLOGY \\ Coupled Eulerian-Lagrangian approach}

The FE calculations here were carried out using the coupled Eulerian-Lagrangian (CEL) approach available in the commercial package Abaqus/Explicit. This large deformation analysis method has the potential to provide a complete penetration resistance profile and to capture the evolving soil flow patterns. Previous applications of the CEL approach for modelling continuous spudcan penetration can be found in Tho et al. (2012), Qiu \& Henke (2011), Qiu \& Grabe (2012) and Hu et al. (2014b). In the CEL approach, the spudcan and soil are discretised using Lagrangian and Eulerian mesh. The Lagrangian mesh is composed of four-node linear tetrahedron elements, whereas the Eulerian mesh is composed of eight-node linear hexahedron elements with reduced integration and hourglass control. The soil mesh remains unchanged throughout the analysis and the soil materials are allowed to flow in or out of each Eulerian element whose nodes have fixed locations. Consequently, mesh distortion (and thus computational non-convergence) is avoided even when the soil is subjected to large deformations. The surfaces or interfaces of the soil materials are tracked by computing the volume fraction of each material within each element. An Eulerian element can be occupied by more than one material simultaneously, while only one material is contained in a Lagrangian element. 
Table 1. Expressions for bearing capacity factors found in literature for spudcan foundations penetrating the underlying clay (after penetrating the top sand layer)

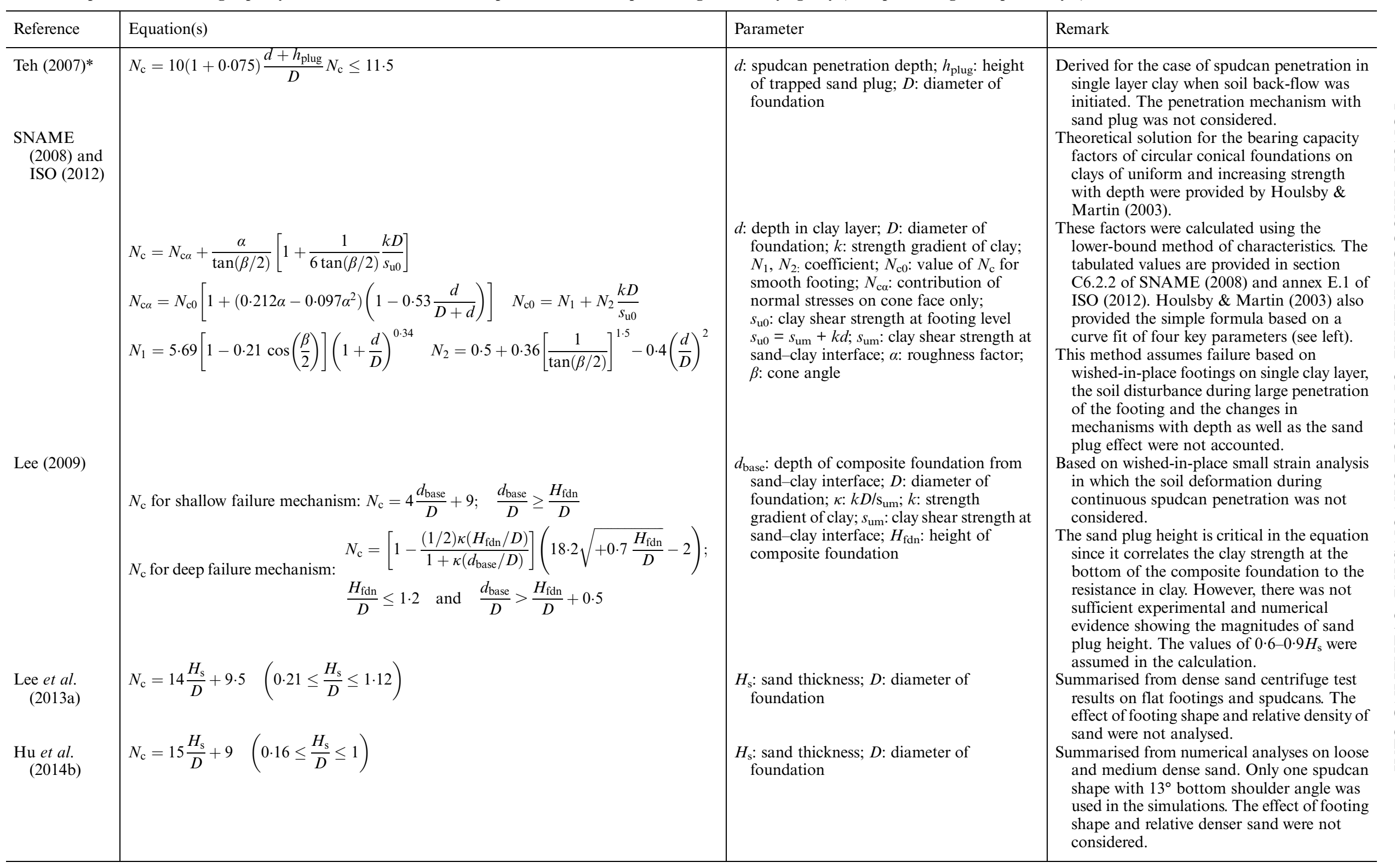

*This formula was used in Teh (2007) and Teh's method was referred in section A.9·3·2 6.4 and clause E.3 of the ISO (2012) guideline. 
The footing is discretised with Lagrangian elements which move through the Eulerian mesh and the penetration resistance is obtained through contact between the footing and soil materials. The frictional footing-sand contact was described by the Coulomb friction law, with the coefficient of friction equal to $\alpha \tan \phi_{\mathrm{cv}}$, where $\phi_{\mathrm{cv}}$ is the constant-volume friction angle of the sand and $\alpha$ is the footing roughness factor. A roughness factor of $\alpha=0.5$ was adopted, which was within the range of $0 \cdot 3-0 \cdot 5$ suggested by SNAME (2008) guidelines, and was also the value used by Qiu \& Henke (2011) and Qiu \& Grabe (2012) in similar analyses. Additionally, it was necessary to define a layer of initially void elements above the mudline to accommodate the soil heave formed by footing penetration.

The penetration of the footing into the soil was simulated in displacement-controlled mode. A constant penetration velocity was specified as $0 \cdot 2 \mathrm{~m} / \mathrm{s}$. After trialling various element sizes, the element size around the footing was selected as $0.025 \mathrm{D}$ to achieve adequate numerical accuracy and efficiency. The dependency of the solution on the mesh density and penetration velocity has been discussed previously in $\mathrm{Hu}$ et al. (2014b). In the Abaqus FE package, the Eulerian technique is only available for three-dimensional elements, hence, to reduce the computational cost and by taking advantage of the axial symmetry of the geometry of the problem, only a quarter of the domain was modelled (see Fig. 2). A fine mesh zone with horizontal extension of $0 \cdot 75 D$ was chosen to cover significant soil movements induced by footing penetration. The coarse mesh zone with horizontal extension of $2.5 \mathrm{D}$ was found to be sufficiently large to minimise the boundary effects. The depth of penetration, $d$, is defined as zero when the lowest elevation of the widest cross-sectional area of the conical footing or spudcan reaches the original soil surface.

\section{Sand model}

Considering the spudcan penetration rate in the experimental investigations ( $\mathrm{Hu}$ et al., 2014a; $\mathrm{Hu}, 2015)$, it is

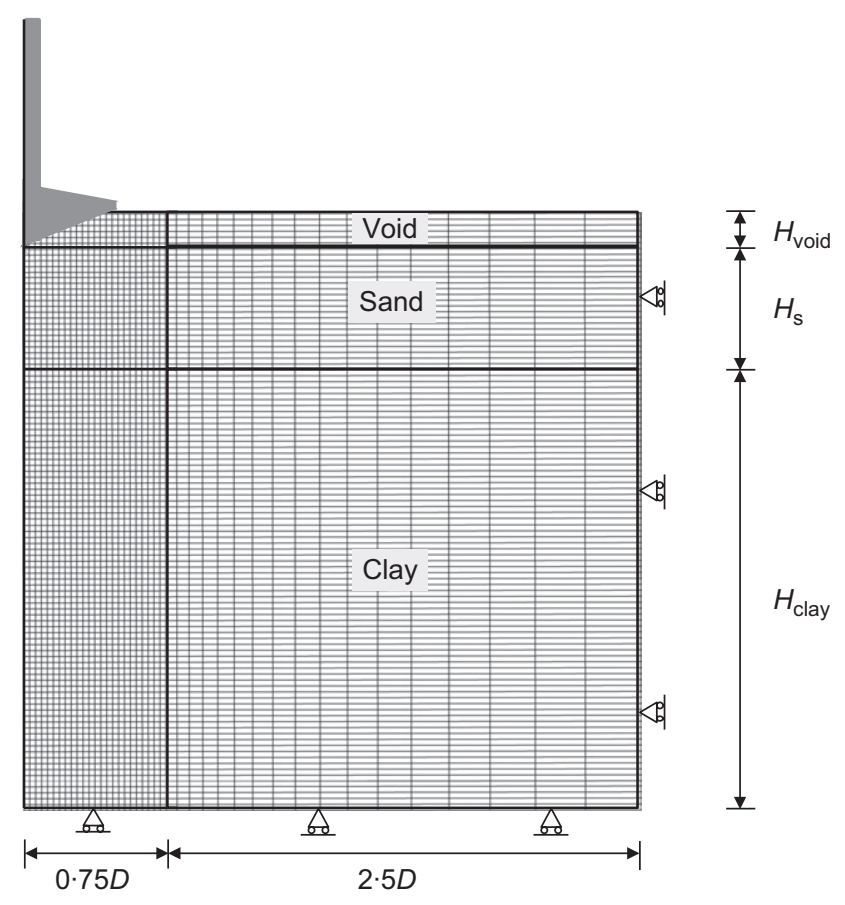

Fig. 2. Finite-element mesh used in a typical CEL analysis (note: $H_{\text {void }}$ and $H_{\text {clay }}$ vary with footing diameter and penetration depth and this is the front view) reasonable to assume that the sand was under drained conditions and the clay was under undrained conditions. Tho et al. (2012) and $\mathrm{Hu}$ et al. (2014b) used the MohrCoulomb (MC) model to represent the mechanical response of sand to spudcan penetration. In its most basic form the MC model does not consider the effect of hardeningsoftening shear strength or variation of the dilatancy of sand, which are particularly critical when modelling the response of dense sand. The behaviour of dense sand was described with a hypoplastic model by Qiu \& Henke (2011) and Qiu \& Grabe (2012).

To describe the shearing behaviour of medium dense or very dense sands in a simple way, the traditional MC model was modified by varying the internal friction angle, $\phi$, and dilation angle, $\psi$, with respect to the accumulated plastic shear strain, $\xi$, as shown schematically in Fig. 3. It was assumed that the friction angle increases linearly from an initial value, $\phi_{\text {ini }}$, to a peak value $\phi_{\mathrm{p}}$, before reducing linearly to $\phi_{\mathrm{cv}}$ when the critical state is approached. The threshold plastic shear strains corresponding to peak friction angle and critical state are denoted as $\xi_{\mathrm{p}}$ and $\xi_{\mathrm{cv}}$, respectively. The dilation angle remains zero when $\xi \leq 1 \%$ and then increases quickly to a peak value, $\psi_{\mathrm{p}}$, at $\xi=1 \cdot 2 \%$. The dilation angle then remains at $\psi_{\mathrm{p}}$ until $\xi_{\mathrm{p}}$, followed by linear reduction back to zero by $\xi_{\mathrm{cv}}$. The dilation angle is simplified as zero while $\xi \leq 1 \%$ since almost all sands are initially contractile before becoming dilatant; however, the MC model cannot converge with negative dilation angles. The incremental plastic shear strain during each incremental step was calculated as

$$
\Delta \xi=\sqrt{\frac{2\left[\left(\Delta \varepsilon_{1}-\Delta \varepsilon_{2}\right)^{2}+\left(\Delta \varepsilon_{2}-\Delta \varepsilon_{3}\right)^{2}+\left(\Delta \varepsilon_{3}-\Delta \varepsilon_{1}\right)^{2}\right]}{3}}
$$

where $\Delta \varepsilon_{1}, \Delta \varepsilon_{2}$ and $\Delta \varepsilon_{3}$ are incremental principal plastic strains measured from the start to the end of the current step. This modified Mohr-Coulomb (MMC) model is similar to that used by Potts et al. (1990, 1997), Dounias et al. (1996) and Troncone (2005); however, both the friction angle and dilation angle are varied with deviatoric plastic strain in this instance, as this was felt to be more realistic. The implementation of this simple model was still within the framework of the MC model: at the end of each incremental step the incremental plastic shear strain is calculated through equation (2) and then the friction and dilation angles at each integration point are updated through the relationships in Fig. 3 for the next step. The updated friction and dilation angles remain constant during the next step.

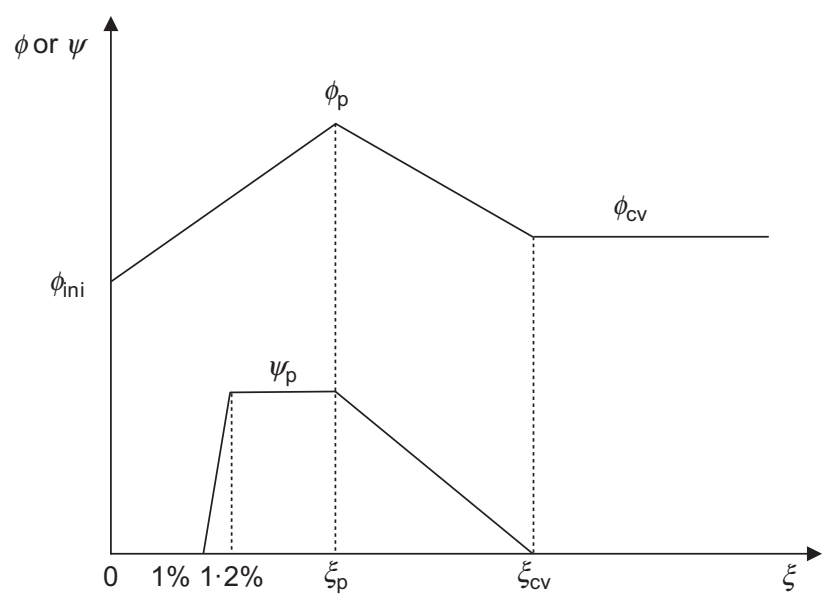

Fig. 3. Variation of the friction angle and dilation angle with deviatoric plastic strain 
In the following analysis, the threshold shear strains were taken as $\xi_{\mathrm{p}}=4 \%$ and $\xi_{\mathrm{cv}}=10 \%$, as observed broadly in triaxial compression tests on super-fine silica sand by Pucker et al. (2013). Similar super-fine silica sands were used in the centrifuge tests of Teh et al. (2008, 2010), Lee et al. (2013a) and $\mathrm{Hu}$ et al. (2014a). The initial friction angle $\phi_{\text {ini }}$ was taken as equal to $\phi_{\mathrm{cr}}$. The peak friction angle $\phi_{\mathrm{p}}$ is taken as a function of both relative density, $I_{\mathrm{D}}$, and the mean effective stress applied on the soil, $p^{\prime}$. The value of $p^{\prime}$ in the penetrations of large-diameter footings is usually lower than $150 \mathrm{kPa}$ (White et al., 2008). The equation of Bolton (1987) was used to calculate the dilatancy index, $I_{\mathrm{R}}$, for $p^{\prime}<$ $150 \mathrm{kPa}$. As it is assumed triaxial conditions applied for the sand around the spudcan for simplification, the peak friction and dilatant angles were calculated based on the empirical axisymmetric formulations proposed by Bolton (1986). The $\phi_{\mathrm{cv}}$ was taken as $31^{\circ}$, which is in agreement with the super-fine silica sand used in the centrifuge tests by Lee et al. (2013a) and $\mathrm{Hu}$ et al. (2014a). It should be noted that only the soil elements on the centreline actually experience axisymmetric deformations. All elements off the centreline experience more complex deformations for which the Bolton's formulations were not originally developed. The Young's moduli of medium dense and dense sand were taken as 25 and $50 \mathrm{MPa}$, respectively. By incorporating this model in the simulation, the post-peak response of the sand is effectively captured through updating the friction and dilation angles with respect to the accumulated strain.

For the case of loose sand $\left(I_{\mathrm{D}} \leq 35 \%\right)$, a hardening instead of softening behaviour is observed under drained conditions and the peak friction angle tends to be similar to or slightly higher than $\phi_{\mathrm{cv}}$. In this instance the modified model reverts to the traditional variant with the internal frictional angle specified as the critical value and the corresponding dilation angle as zero.

\section{Clay model}

The clay layer under undrained conditions was modelled as an elastic-perfectly plastic material obeying the Tresca yield criterion incorporating strain softening effects. Similar to the implementation of the MMC model in the sand layer, the undrained shear strength at the integration points representing clay were updated at the end of each incremental step according to the accumulated plastic shear strain (Einav \& Randolph, 2005)

$$
s_{\mathrm{u}}=\left[\delta_{\text {rem }}+\left(1-\delta_{\text {rem }}\right) \mathrm{e}^{-3 \xi / \xi_{95}}\right] s_{\mathrm{ui}}
$$

where $s_{\mathrm{u}}$ is the remoulded undrained shear strength; $\delta_{\text {rem }}$ denotes the ratio of fully remoulded and intact shear strengths (i.e. the inverse of the sensitivity, $S_{\mathrm{t}}$ ); $\xi_{95}$ represents the value of $\xi$ required for the soil to undergo $95 \%$ remoulding, estimated in the range of $10-50$ for marine clays (Zhou \& Randolph, 2009); and $s_{\text {ui }}$ is the intact undrained shear strength of the clay, which was usually measured from penetrometer (e.g. T-bar or cone) tests. The undrained strength updated through equation (3) was kept constant during the calculations of the next step time. Because the penetration resistance is nearly independent of the soil rigidity (Qiu \& Henke, 2011; Tho et al., 2012), a typical Young's modulus of $500 s_{\mathrm{u}}$ was used. The Poisson ratio was 0.49 to approximate constant-volume shearing under undrained conditions.

\section{NUMERICAL ANALYSIS \\ Performance of the MMC model and Tresca model}

The performance of the MMC and Tresca constitutive models is first validated against a test with very dense sand overlying clay from Lee et al. (2013a). The sand sample was a fine silica sand with $I_{\mathrm{D}}=92 \%$, and the friction and dilation angles were $\phi_{\mathrm{p}}=41 \cdot 8^{\circ}, \phi_{\mathrm{cv}}=31^{\circ}$ and $\psi_{\mathrm{p}}=22 \cdot 5^{\circ}$ (see Table 2). The clay shear strength at the sand-clay interface, $s_{\text {um }}$, was $17.7 \mathrm{kPa}$ and shear strength increased linearly with a gradient $k=2 \cdot 1 \mathrm{kPa} / \mathrm{m}$, measured using T-bar penetrometer tests. Sensitivity was measured as $S_{\mathrm{t}}=3$ and an intermediate value of 25 was assigned to $\xi_{95}$. The performances of the MMC and MC models are compared in Fig. 4, highlighting the enhancement provided by the MMC model.

When the MC model with peak friction and dilation angles is employed, the penetration resistance continues to increase monotonically and the punch-through failure observed in the centrifuge test is not captured. The penetration resistance is overestimated significantly since the strength degradation of sand during the post-peak stage has not been described. If the friction angle in the MC model is taken as the one at critical state and the corresponding dilation angle is zero, the peak resistance in the sand layer is significantly underestimated and the punch-through potential is not predicted well. In contrast, the MMC model results in a reasonable reproduction of the test. A sharp increase in penetration resistance to the peak value is observed, which is followed by a significant reduction of resistance during subsequent penetration in the sand layer. With further penetration in the clay layer, the resistance is recovered gradually due to the undrained strength of clay increasing with depth. The difference in peak resistance predicted is within $10 \%$, and the experimental and numerical resistance profiles in the clay layer agree well with each other.

In order to obtain more confidence in the application of MMC and modified Tresca models, three series of centrifuge tests with various soil properties and footing geometries were simulated. These consisted of five tests in very dense sands from Lee et al. (2013a), nine tests in very dense or medium dense sands from Teh et al. (2010) and 11 tests in medium dense sands from $\mathrm{Hu}$ (2015). The details of these tests and all the parameters are provided in Table 2. Among a total number of 25 tests, two typical tests from each testing series are presented in Fig. 5 for clarity. The robustness of the CEL approach incorporating the constitutive models developed is further verified through the generally reasonable agreement between the experimental and numerical penetration resistance profiles. The peak resistances predicted are usually moderately lower than those measured; however, the differences are less than $15 \%$ for the majority of the cases. One possible reason for the underestimation (especially for dense sand) is that, in the CEL simulations, the mean stress along the sand failure surface is typically moderately lower than $150 \mathrm{kPa}$ when $q_{\text {peak }}$ is mobilised, thus the $\phi_{\mathrm{p}}$ and $\psi_{\mathrm{p}}$ corresponding to such lower stress level will be higher than those calculated using Bolton's equation (White et al., 2008). More recently, Andersen \& Schjetne (2013) reported practical values of $\phi_{\mathrm{p}}$ and $\psi_{\mathrm{p}}$ at different confining stress levels according to a database with more than 500 triaxial compression tests on 54 different onshore and offshore sands. According to the magnitude of confining stress observed in the CEL analysis for test UWA_F3 in Fig. 6, $50 \sim 110 \mathrm{kPa}$, the values of $\phi_{\mathrm{p}}=45^{\circ}, \psi_{\mathrm{p}}=19^{\circ}$ and $\phi_{\mathrm{cv}}=37^{\circ}$ were determined from the fitting curves of Andersen \& Schjetne (2013). Although the prediction of $q_{\text {peak }}$ is improved, as shown in Fig. 5(b) for the above parameters, they were not used in the parametric simulations. Reasons for this choice were: (a) Bolton's equations provide fast, automated and acceptable estimation of the input parameters for the CEL analyses. The confining stress levels tend to increase during further penetration after peak resistance; and $(b)$ the testing data in Andersen \& Schjetne (2013) were scattered over a relatively large range. 
Table 2. Summary of centrifuge tests and numerical simulations

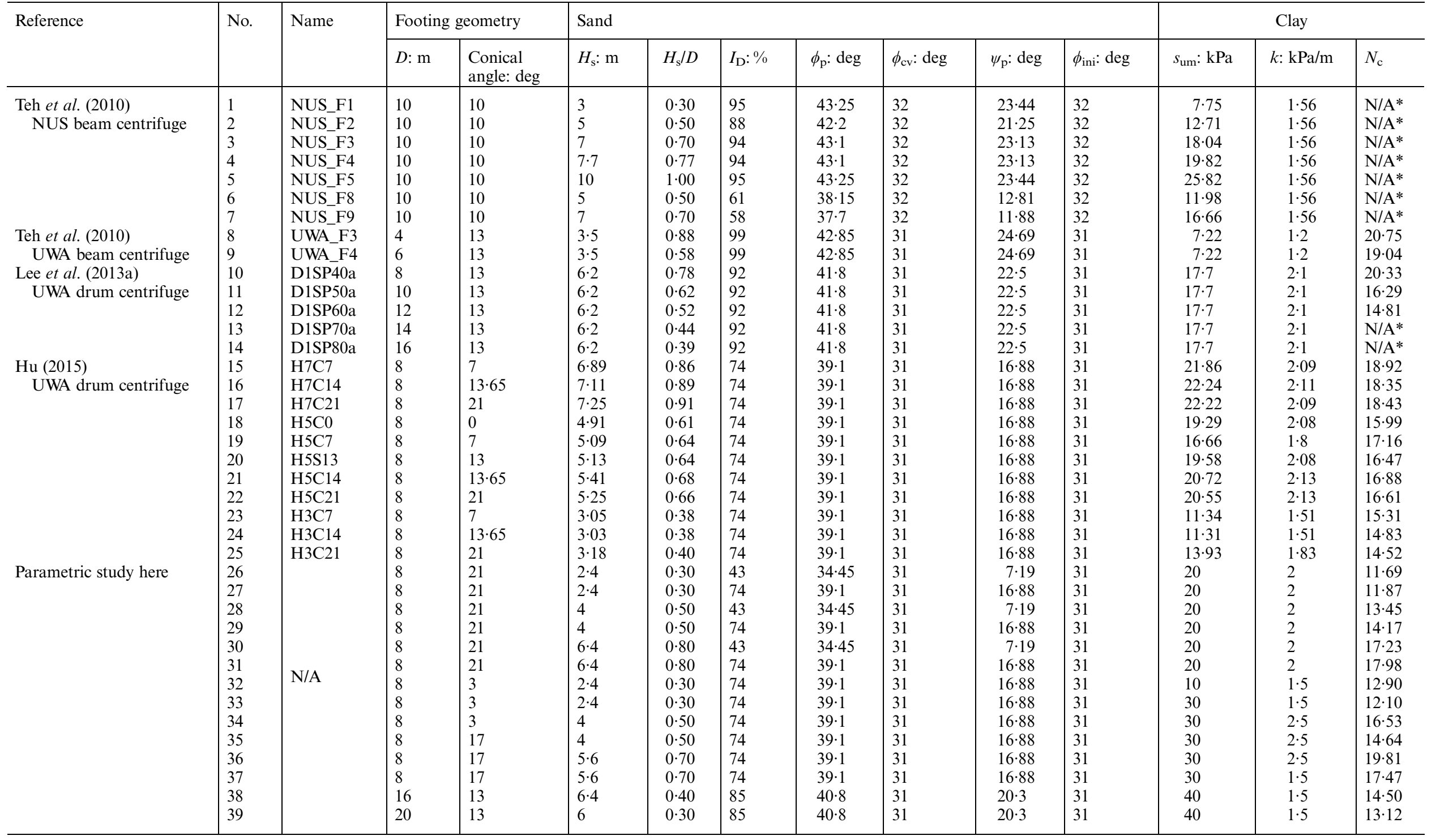

Note: The bearing capacity factors corresponding to tests are from CEL.

*The value of $N_{\mathrm{c}}$ (at $1 D$ below the interface) is not available. 


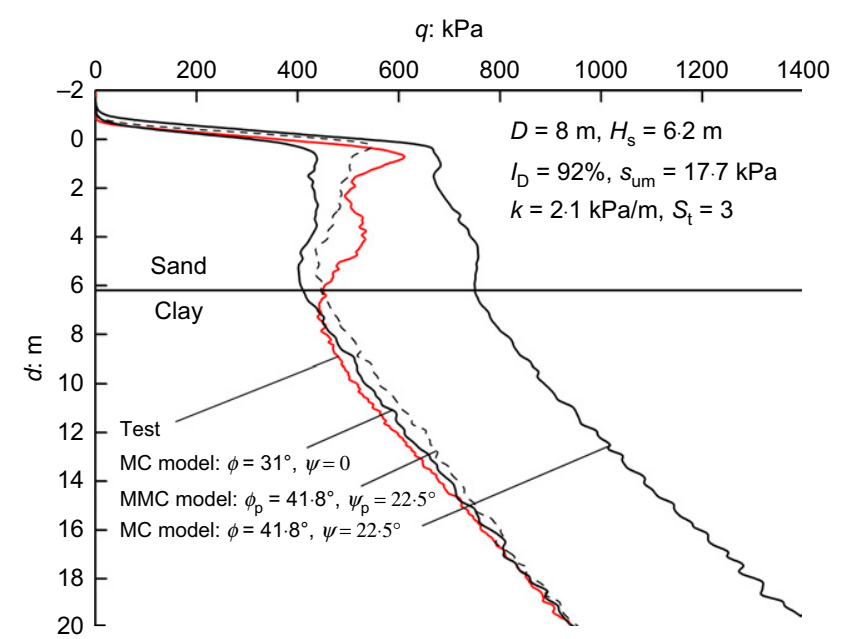

Fig. 4. Performance of the MMC model by comparison with centrifuge test and MC model

Based on Lee et al. (2013b), Hu et al. (2014a) presented an analytical model to estimate the peak resistance. The model was calibrated through experimental data from medium dense to very dense sands and for a spudcan geometry with main conical angle of $13^{\circ}$, and has been further validated for various footing shapes with conical angle ranging from 0 to $21^{\circ}(\mathrm{Hu}, 2015)$. The peak resistances predicted by the analytical model and CEL analyses compared to published experimental measurements are plotted in Fig. 7. Compared with the predictions from the analytical model by $\mathrm{Hu}$ et al. (2014a), most numerical and almost all experimental data are located within bounds of $\pm 15 \%$.

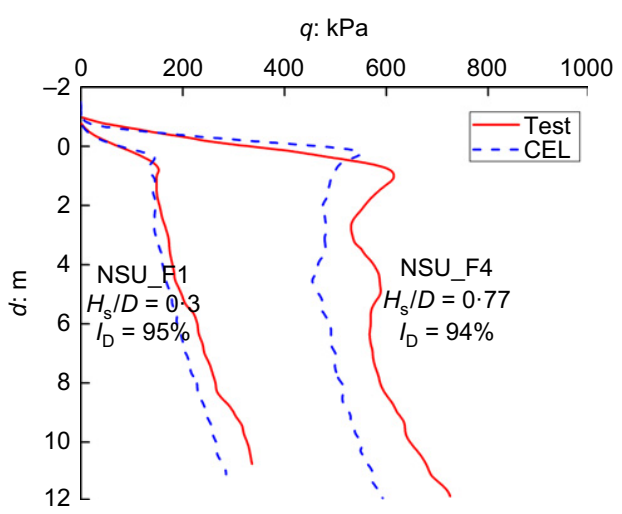

(a)

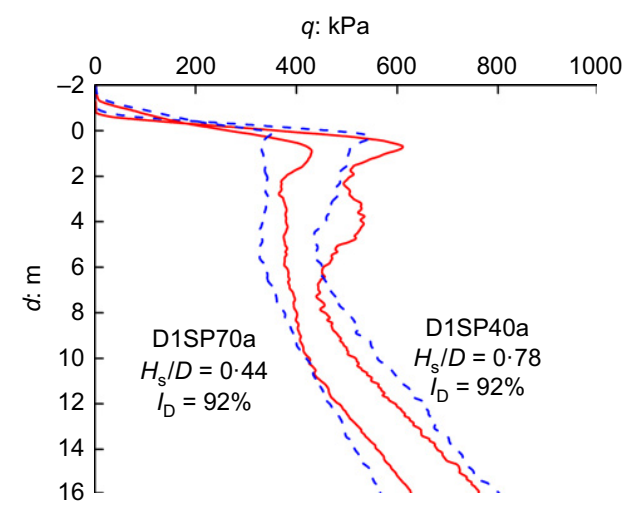

(c)
Evolution of friction angles and penetration resistance

The evolution of the friction angle for a typical test (H5S13 in Table 2, for spudcan with conical angle of $13^{\circ}$ ) is shown in Fig. 8, in order to illustrate distributions of mobilised friction angles in the sand at different penetration depths. The experimental and numerical resistance profiles are provided in Fig. 5(d). When the bottom shoulder of the spudcan was fully embedded in the sand (i.e. $d=0$ ), only the sand beneath the shoulder was sheared to the critical state. The friction angle of the sand in the outer region was then gradually mobilised towards the peak value with further penetration. The horizontal extension of the influence zone is as large as $1 D$ from the centreline of the spudcan in Fig. 8(a). When the depth of peak resistance, $q_{\text {peak }}$, is reached, the influence zone has propagated wider and deeper, with more sand mobilised to a depth of $0 \cdot 8 D$ (Fig. 8(b)). For subsequent penetration from the depth of peak resistance, the bearing capacity of clay was enhanced. More sand flows back to the top of the spudcan, acting as surcharge and contributing to the reduction in total penetration resistance. At the depth of the original sand-clay interface, the majority of the sand around the advancing spudcan has reached the critical state and the minimum magnitude of penetration resistance was observed.

\section{Evolution of soil and sand plug geometry}

In the thesis by $\mathrm{Hu}(2015), 11$ half-footing penetration tests (against a poly(methyl methacrylate) window) were conducted to investigate the footing shape effect and to visualise the soil flow mechanisms using the PIV technique. For penetration from occurrence of $q_{\text {peak }}$ to $1 D$ below the original sand-clay interface (for test $\mathrm{H} 5 \mathrm{C} 0$ in Table 2, flat footing), the soil displacement vectors interpreted through the PIV analysis are displayed on the left side of Fig. 9. The water-sand and

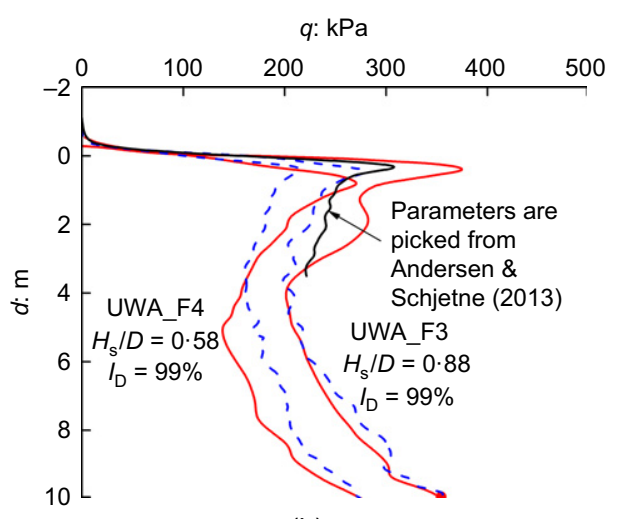

(b)

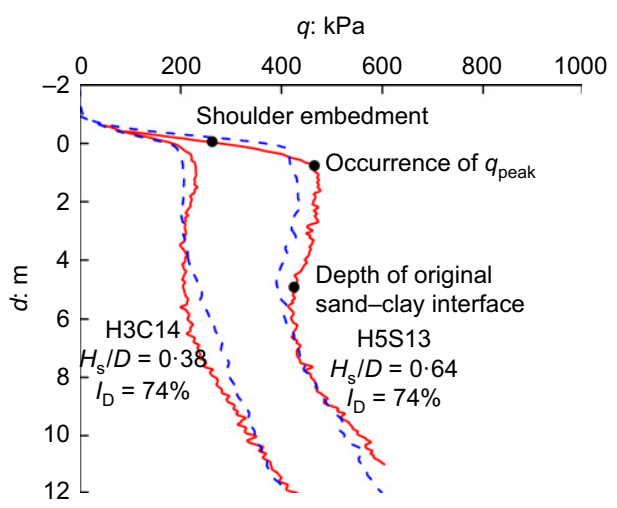

(d)

Fig. 5. Full penetration resistance profiles from centrifuge tests and numerical analyses 


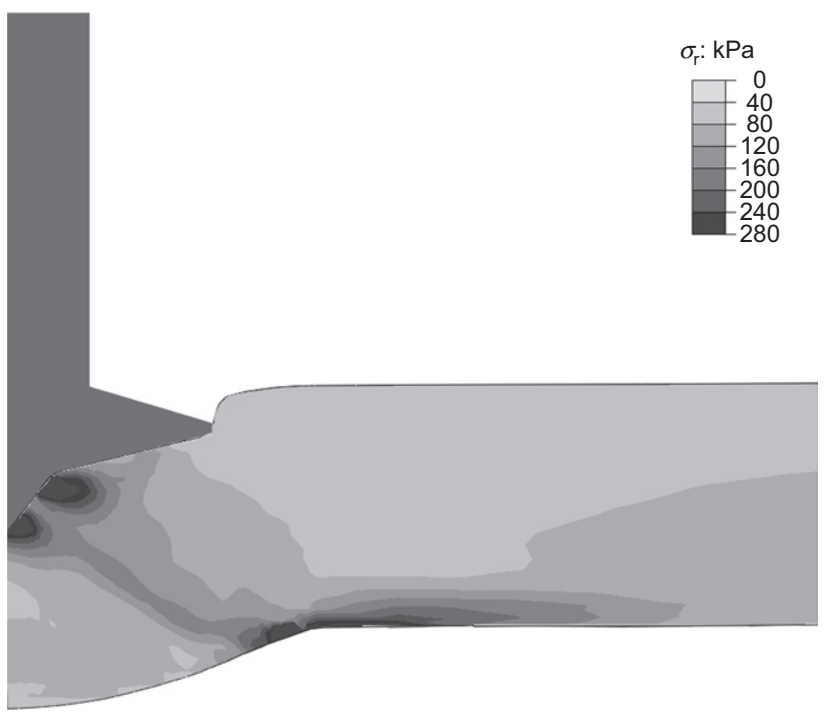

Fig. 6. Confining stress contours at $q_{\text {peak }}$ for test UWA_F3

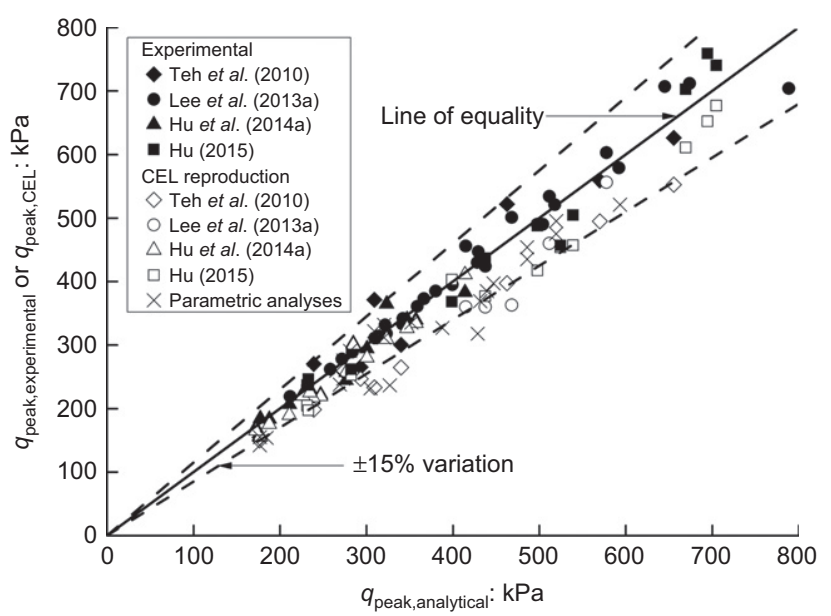

Fig. 7. Comparison of peak resistances from analytical model of $\mathrm{Hu}$ et al. (2014a) and that from centrifuge tests and numerical analyses

sand-clay layer interfaces are indicated by two lines in the left-hand side of Fig. 9. The flow mechanism cannot be generated in a similar way in the CEL analysis since the velocities at the Eulerian nodes may not represent the physical/ Lagrangian movements (Dassault Systèmes, 2011). Therefore, the deformed geometries of the sand and clay layers and the contours of clay shear strength are shown on the right-hand side of Fig. 9. In general, the sand plug shape and layer interface positions measured using PIV and the numerical soil deformations are consistent with each other.

Although $q_{\text {peak }}$ occurs at a relatively shallow depth in the sand layer, obvious movements appear in the clay beneath the sand-clay interface in Fig. 9(a). This deformation might be idealised as a sand frustum beneath the footing moving downward and causing mobilisation of surrounding clay. Hence $q_{\text {peak }}$ is the sum of the frictional resistance along the slip surface in the sand (see Fig. 6) and the bearing capacity of the underlying clay minus the weight of the sand frustum, as reflected in the analytical model of $\mathrm{Hu}$ et al. (2014a). A sand wedge of truncated conical shape is pushed into the clay layer when the footing penetrates to the original sand-clay interface (Fig. 9(b)). The indentation of the sand wedge into the underlying clay squeezes clay outwards but the sand plug is not yet fully formed. Deeper soil with higher undrained

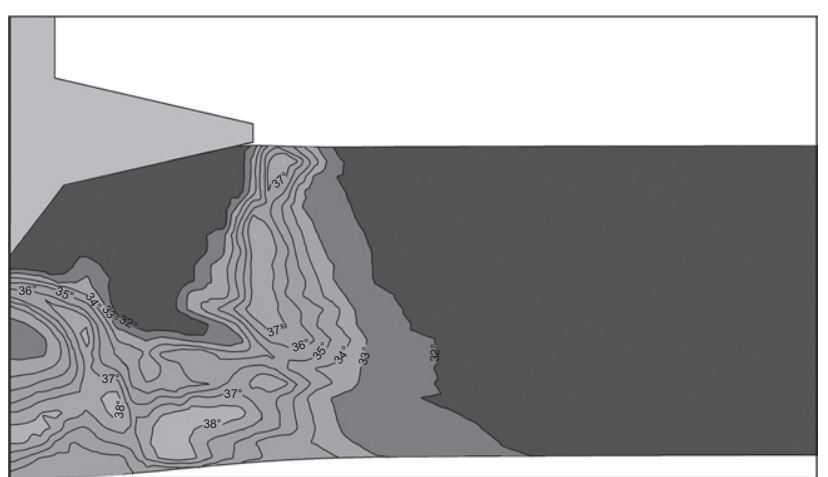

(a)

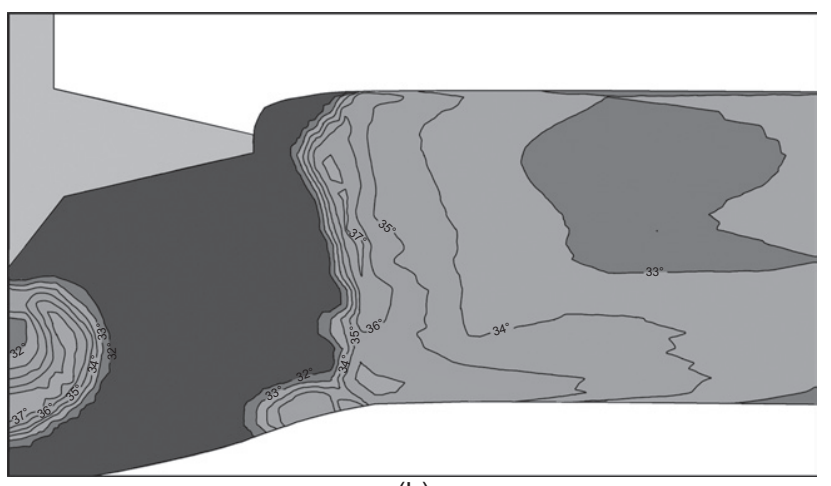

(b)

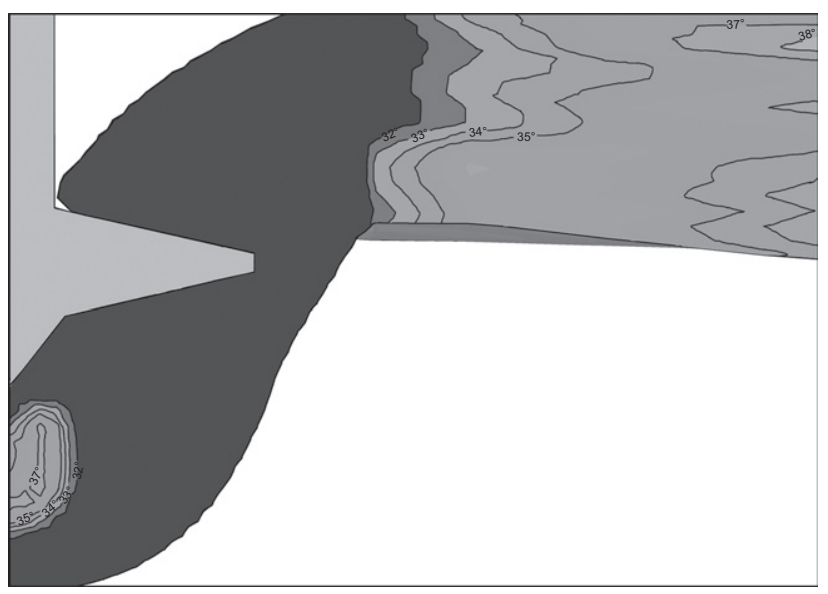

(c)

Fig. 8. Friction angle contours at typical penetration depths for simulation of centrifuge test $\operatorname{H5S13}\left(\phi_{\mathrm{p}}=39 \cdot 1^{\circ}, \phi_{\mathrm{cv}}=31^{\circ}\right)$ : (a) shoulder embedment; (b) occurrence of $q_{\text {peak }}$; (c) original sand-clay interface

strength is mobilised by the downward-moving sand wedge, resulting in increased penetration resistance. At $0.5 \mathrm{D}$ below the interface (Fig. 9(c)), the sand plug is fully formed and its shape and height remained nearly unchanged as it is advanced further in the clay. The penetration resistance is exerted by stronger clay at the sand plug base rather than at the spudcan bottom. The top layer sand continues to fall into the cavity formed above the footing. When the footing penetrates to $1 D$ below the interface in Fig. 9(d), the failure mechanism stabilises. For the underlying clay layer, the movement of the clay changed from vertical to radial and finally tailed off to horizontal flow in the far field. Minor soil heave is found in the far-field of the soil surface, but the magnitude of soil upheaval measured in the present study is relatively small. The stable sand plug height underneath this flat footing was measured as $0 \cdot 89 H_{\mathrm{s}}$. 


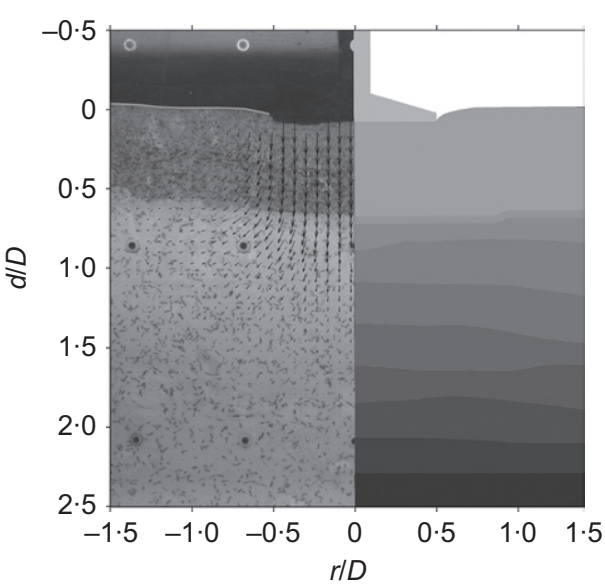

(a)

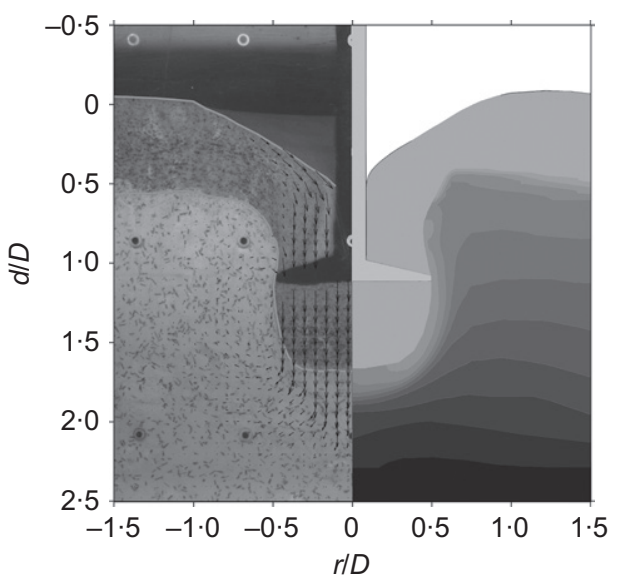

(c)

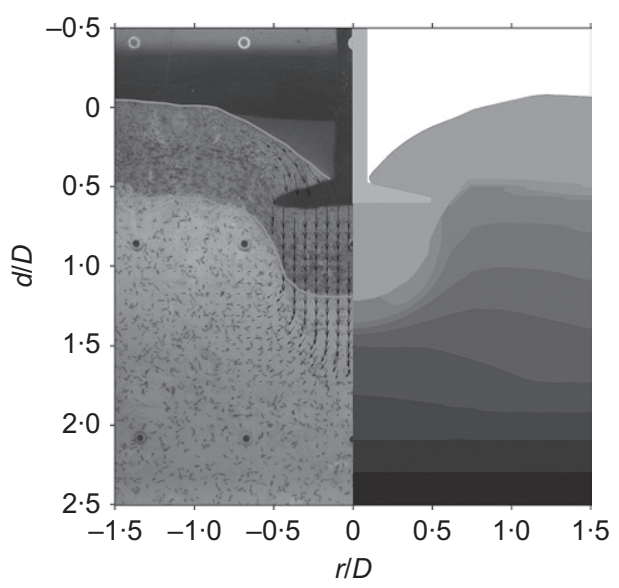

(b)

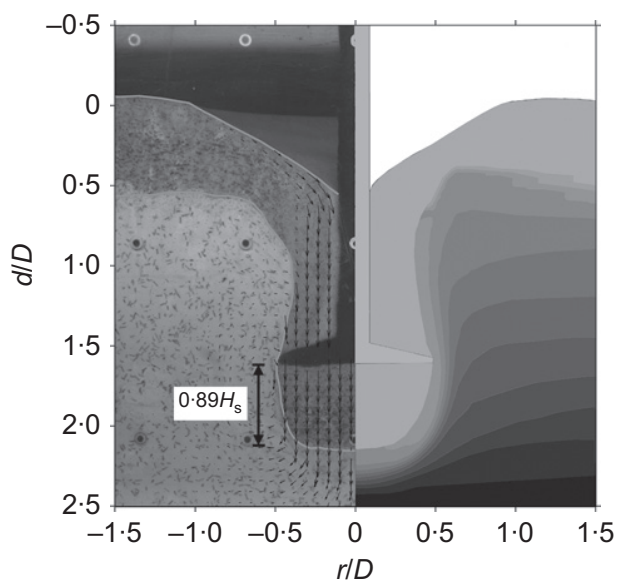

(d)

Fig. 9. Evolvement of soil and sand plug with footing penetration for test $\mathrm{H5C0}$ (sand thickness $4.91 \mathrm{~m}$, footing diameter $8 \mathrm{~m}$ ) (LHS: experimental PIV; RHS: CEL analysis): (a) occurrence of $q_{\text {peak }}$; (b) interface; (c) $0.5 D$ below interface; (d) $1 D$ below interface

The deformed soil layers corresponding to footings with conical angle of $14^{\circ}$ and $21^{\circ}$ (test $\mathrm{H} 3 \mathrm{C} 14$ and $\mathrm{H} 3 \mathrm{C} 21$ ) are shown in Fig. 10. The stable sand plug height from the numerical simulations agree well with those measured in the centrifuge tests, with height of $0.96 H_{\mathrm{s}}$ for $14^{\circ}$ angle and $0.98 H_{\mathrm{s}}$ for $21^{\circ}$ angle. By comparing Fig. 9(d) and Fig. 10, the sand plug height increases slightly in proportion with the increase in footing conical angle, but the effect is minimal. In all the PIV measurements and corresponding CEL analyses, the bottom of the sand plug has a relatively flat surface and its width is approximately equivalent to the diameter of the footing. Therefore, it is appropriate to assume that the sand plug is cylindrical in shape with diameter, $D$, and height, $h_{\text {plug }}$, when constructing a simplified method to calculate the bearing capacity in the clay layer.

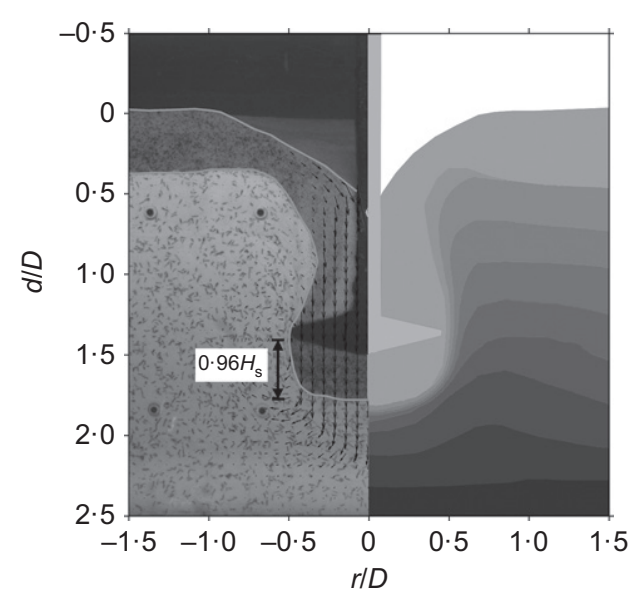

(a)

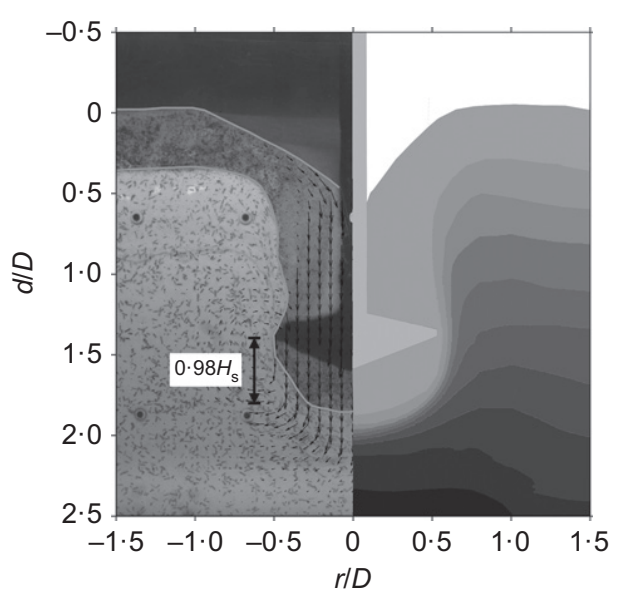

(b)

Fig. 10. Sand plug heights for tests $\mathrm{H} 3 \mathrm{C} 14$ and $\mathrm{H} 3 \mathrm{C} 21$ (1D below sand-clay interface): (a) H3C14; (b) H3C21 
BEARING CAPACITY FACTOR AND

\section{PUNCH-THROUGH DISTANCE}

Bearing capacity factor in clay layer

In addition to the 25 centrifuge tests (see Table 2) replicated, a total number of 14 supplemental simulations were performed to back-calculate the bearing capacity factor, $N_{\mathrm{c}}$, in the clay layer to further quantify possible combined influence of critical factors (e.g. footing shape, $H_{\mathrm{s}} / D, I_{\mathrm{D}}, s_{\mathrm{um}}$ and $k$ ) within realistic bounds relevant to offshore practice. Following the same procedure as $\mathrm{Hu}$ et al. (2014b), the $N_{\mathrm{c}}$ was derived at $1 D$ below the sand-clay interface by applying equation (1) to the testing and numerical data with the sand plug height taken as $0 \cdot 9 H_{\mathrm{s}}$. The sand properties were taken to be the same as the super-fine silica sand used in the centrifuge tests in Lee et al. (2013a) and $\mathrm{Hu}$ et al. (2014a), with $I_{\mathrm{D}}=$ $43 \%, 74 \%$ and $85 \%$; the sand thickness ratio $H_{\mathrm{s}} / D$ is varied from $0 \cdot 3$ to $0 \cdot 8$; clay shear strength at the sand-clay interface $s_{\text {um }}$ ranges from 10 to $40 \mathrm{kPa}$; clay strength gradient $k$ is between 1.5 and $2.5 \mathrm{kPa} / \mathrm{m}$; and the footing conical angle varies from 3 to $21^{\circ}$. A value of 3 for soil sensitivity of kaolin clay is used, which is based on the experimental measurements of $\mathrm{Hu}$ et al. (2014a) and close to the $S_{\mathrm{t}}$ value of $2 \cdot 5$ reported by Zhang et al. (2011) and $2-2 \cdot 5$ reported by Gan et al. (2012). The aim of selecting the above parameters is to cover more footing shapes and soil properties that have not appeared in the centrifuge tests performed. The details of the geometric and soil property parameters and the resulting $N_{\mathrm{c}}$ are listed in Table 2. For the combined experimental and numerical dataset constituting all cases in Table 2 and the experimental and numerical data of Lee et al. (2013a) and Hu et al. (2014b), the variation of $N_{\mathrm{c}}$ with the sand thickness ratio and normalised clay strength is shown in Fig. 11. This combined dataset consists of 52 centrifuge tests.

Although there may be theoretical reasons to expect a variation in $N_{\mathrm{c}}$ with normalised clay strength, as seen in $N_{\mathrm{c}}$ factors for footings in single layer clays, this is hard to decipher from the available dataset. Partially this may be because of the method of laying the experimental sample, with the sand layer initially laid to produce an overconsolidated clay and then progressively scraped back to produce lower $H_{\mathrm{s}} / D$ experiments (for details see Lee et al. (2013a) and $\mathrm{Hu}$ et al. (2014a)). This caused the high $\mathrm{kD} / \mathrm{s}_{\text {um }}$ experiments $(>2 \cdot 0)$ to be at low $H_{\mathrm{s}} / D$ ratios $(<0 \cdot 3)$. This can be seen in Fig. 11. However, the primary reason is that the $H_{\mathrm{s}} / D$ ratio is more dominant in determining the $N_{\mathrm{c}}$ factors in the underlying clay. This can be observed both in the trend of Fig. 11 (strong correlation of increasing $N_{\mathrm{c}}$ with $H_{\mathrm{s}} / D$ ) and

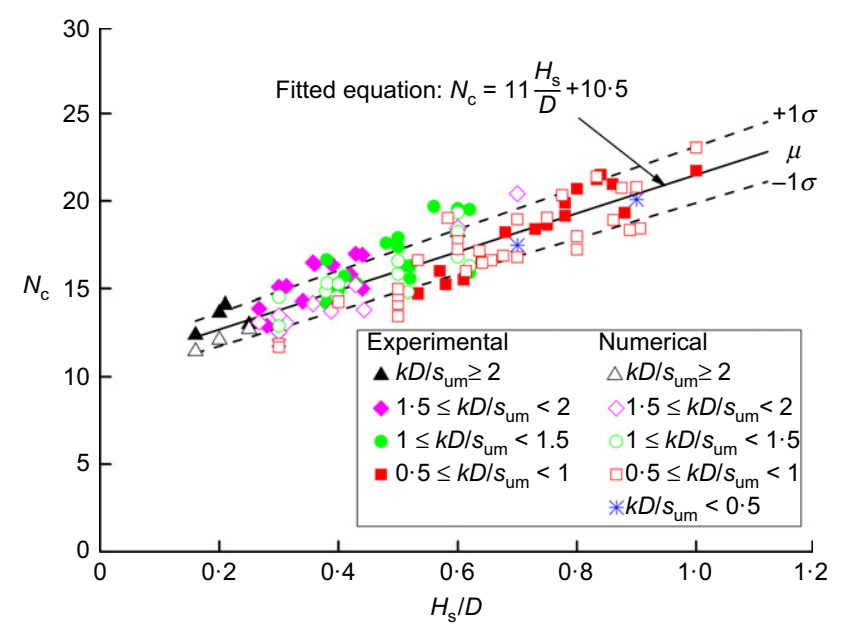

Fig. 11. Bearing capacity factors from all the experimental and numerical analyses when comparing $N_{\mathrm{c}}$ factors for changing $\mathrm{kD} / \mathrm{s}_{\mathrm{um}}$ in a single layer clay (i.e. no sand plug). Using the lower bound factors of Houlsby \& Martin (2003), as now quoted in the ISO (2012) and repeated in Table 1 , equivalent $N_{\mathrm{c}}$ factors for an inverted conical footing with main conical angle of $13^{\circ}(\beta=$ $154^{\circ}$ in Table 1), roughness of 0.5 and at a depth of $1 D$ (as close to the conditions here) would be $N_{\mathrm{c}}=7 \cdot 39$ for $\mathrm{kD} / \mathrm{s}_{\mathrm{um}}=$ 0 and $N_{\mathrm{c}}=7 \cdot 50$ for $k D / s_{\mathrm{um}}=3$. The difference in the $N_{\mathrm{c}}$ with $\mathrm{kD} / \mathrm{s}_{\text {um }}$ varying from 0 to $3 \cdot 0$ is only $1 \cdot 5 \%$. When compared to the change in $H_{\mathrm{s}} / D$ ratio in Fig. 11 this could only be considered a secondary effect.

For these reasons the authors report $N_{\mathrm{c}}$ factors as a function of $H_{s} / D$ only, leaving any further refinement with normalised clay strength, $k D / s_{\text {um }}$, for when more conclusive data are available. An equation that fits all these experimental and numerical data is

$$
N_{\mathrm{c}}=11 \frac{H_{\mathrm{s}}}{D}+10 \cdot 5\left(0 \cdot 16 \leq \frac{H_{\mathrm{s}}}{D} \leq 1 \cdot 12\right)
$$

Statistical analysis is further performed to quantify the uncertainties and scatter of the data in order to account for them in a rational and consistent manner that may be applied in design to give upper and lower bounds on the penetration resistance in the clay layer. As shown in Fig. 11, the variability of $N_{\mathrm{c}}$ is most easily expressed by assuming that it follows a normal distribution with a best fit represented by its mean (calculated from equation (4)) and bounds represented by its standard deviation. The corresponding coefficient of variation $(\mathrm{COV})$ is $7 \cdot 5 \%$, indicating low variation. This facilitates establishment of a range of punch-through distance predictions for spudcans on sand overlying clay, which will be discussed in the next section. The expression for bearing capacity factor is verified by comparison with those from all the centrifuge tests, plotting according to the relative density of sand and footing conical angle in Fig. 12. As expected, although the data points are somewhat scattered around the best-fit line of equation (4), neither the relative density of the sand or the footing conical angle has a significant or systematic effect on $N_{\mathrm{c}}$. In the application of equation (4), the standard deviation of the fitting equation can be added or subtracted from the best-fit line to yield bounds that cover the variability characterised by the scatter of the data points for the various footing geometries and soil conditions.

Prediction of full resistance profile and punch-through distance

$\mathrm{Hu}$ et al. (2014b) presented a simplified method to construct full resistance profile for medium dense sand overlying clay. The bearing capacity factor in clay is updated currently to equation (4), with the resistance in the clay layer obtained by substituting equation (4) into equation (1). The peak resistance in the sand layer occurs at $0 \cdot 12 H_{\mathrm{s}}$. The punch-through distance is calculated as the distance from the depth of $q_{\text {peak }}$ to the depth where $q_{\text {clay }}$ equals $q_{\text {peak }}$ in the underlying clay layer. The equations for calculating the penetration resistances in the full profile have been coded in a Microsoft Excel spreadsheet for quick application. The predictions based on the best-fit equation, equation (4), are appropriate for a basic evaluation. To the authors' knowledge, almost all the sand overlying clay centrifuge tests reported in the literature in which punch-through failures were observed are listed in Table 2. The punch-through distances predicted are presented in Fig. 13. The majority of the predictions of the punch-through distance are within $\pm 20 \%$ of the measured ones. The under-prediction of the punch-through distance may be partially due to the underestimation of $q_{\text {peak }}$ and partially due to the overestimation of 


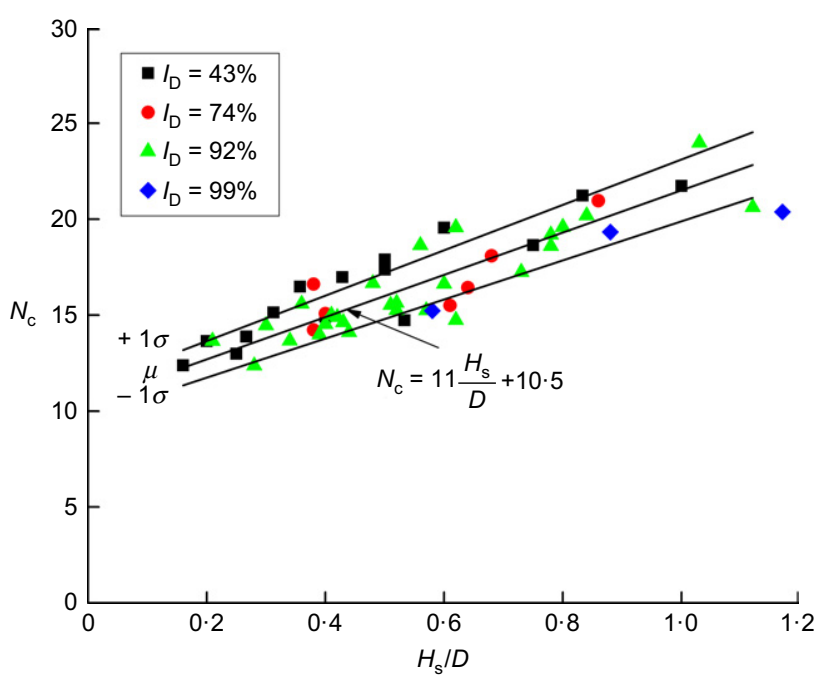

(a)

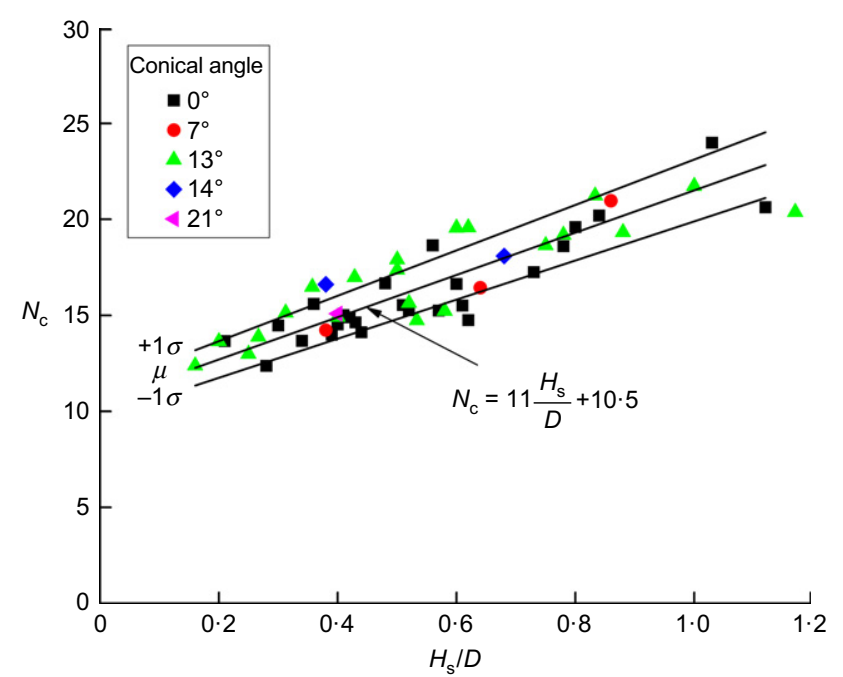

(b)

Fig. 12. Comparison of the new expression for $N_{c}$ with values back-calculated from centrifuge tests: (a) effect of relative density of sand; (b) effect of footing conical angle

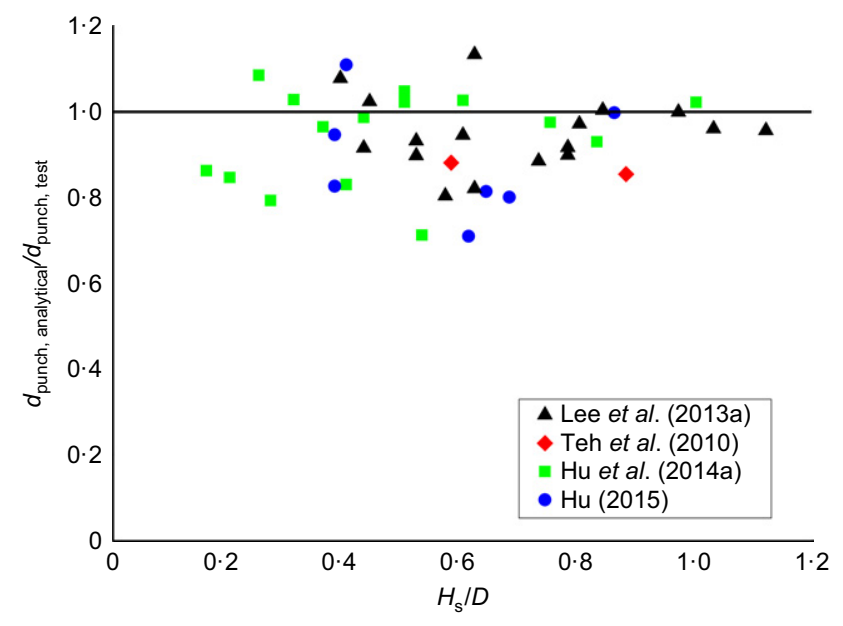

Fig. 13. Performance of the updated full profile prediction method

the bearing capacity factor, which leads to larger predicted penetration resistance in the underlying clay layer.

While an accurate estimation of the actual penetration depth is required for jack-up installation, the use of statistical analysis on the bearing capacity factor, making reasonable allowance for scatter, is beneficial for desk-based risk assessment purposes. Calculating the mean together with \pm 1 standard deviation $(\sigma)$ is often recommended within industry practice (Lacasse et al., 2007) (representing the 15.9 and 84.1 percentile of a normal distribution), although of course different confidence intervals could also be used (e.g. $\pm 1.645 \sigma$ representing the 5 and 95 percentile). Therefore, additional predictions of the punch-through distance based on the addition or subtraction of one standard deviation of $N_{\text {c }}$ provide an easy estimate of the range of uncertainty in the model prediction. For each spudcan penetration case, the calculation is repeated three times, with the $N_{\mathrm{c}}$ adjusted according to the values specified by their statistical distribution. Two typical centrifuge tests, $\mathrm{H} 3 \mathrm{C} 14$ and D1SP40a in Table 2, are analysed to illustrate the potential of this simple statistical implementation, as demonstrated in Fig. 14. The critical stages from the tests are captured from the predicted full profile and the simple prediction fits the testing curve reasonably well. The punch-through distance measured in test D1SP40a is $11.83 \mathrm{~m}$, compared with a predicted value of $10.65 \mathrm{~m}$ through the mean value and ranged between 9.63 and $11.84 \mathrm{~m}$ through $\pm 1 \sigma$. All the predictions of the punch-through distance based on this simple statistical treatment are summarised in Table 3.

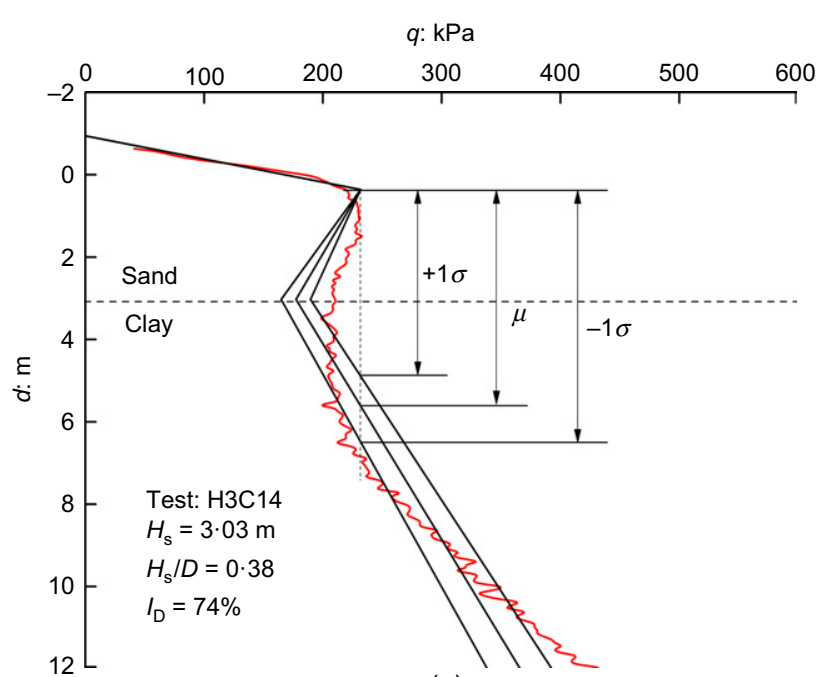

(a)

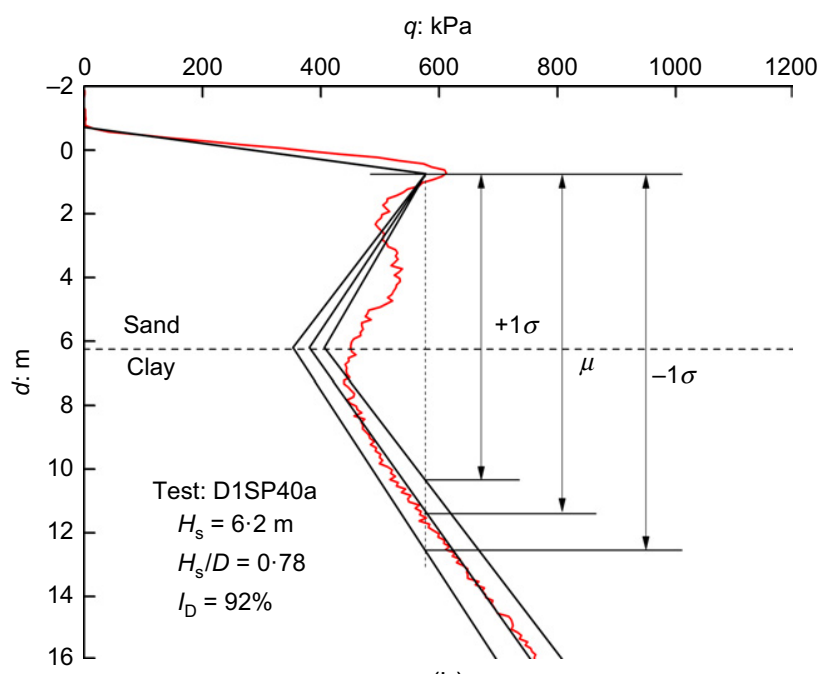

(b)

Fig. 14. Prediction of the punch-through distance using the proposed method with mean and \pm 1 standard deviation for $N_{\mathrm{c}}$ : (a) $\mathrm{H3C14}$; (b) D1SP40a 
Table 3. Predictions of punch-through distance based on best-fit expression and \pm 1 standard deviation for $N_{c}$

\begin{tabular}{|c|c|c|c|c|c|}
\hline Reference & No. & Test name & $d_{\text {punch, test }}: \mathrm{m}$ & $\mu: \mathrm{m}$ & $\pm 1 \sigma: \mathrm{m}$ \\
\hline \multirow[t]{2}{*}{ Teh et al. (2010) } & 1 & UWA_F3 & $10 \cdot 33$ & $8 \cdot 83$ & $7 \cdot 98-9 \cdot 83$ \\
\hline & 2 & UWA_F4 & $9 \cdot 16$ & $8 \cdot 08$ & $7 \cdot 28-9 \cdot 01$ \\
\hline \multirow[t]{5}{*}{ Lee et al. (2013a) } & 3 & D1SP40a & $11 \cdot 83$ & $10 \cdot 65$ & $9 \cdot 63-11 \cdot 84$ \\
\hline & 4 & D1SP50a & $9 \cdot 15$ & $10 \cdot 38$ & $9 \cdot 38-11 \cdot 54$ \\
\hline & 5 & D1SP60a & $11 \cdot 33$ & $10 \cdot 17$ & $9 \cdot 18-11 \cdot 32$ \\
\hline & 6 & D1SP70a & $9 \cdot 77$ & $10 \cdot 01$ & $9 \cdot 04-11 \cdot 15$ \\
\hline & 7 & D1SP80a & $9 \cdot 16$ & $9 \cdot 88$ & $8 \cdot 92-11 \cdot 02$ \\
\hline \multirow[t]{15}{*}{ Hu et al. (2014a) } & 8 & L1SP1 & $7 \cdot 78$ & $7 \cdot 95$ & $7 \cdot 15-8 \cdot 89$ \\
\hline & 9 & L1SP2 & $8 \cdot 10$ & $7 \cdot 91$ & $7 \cdot 11-8 \cdot 85$ \\
\hline & 10 & L1SP3 & $7 \cdot 66$ & $7 \cdot 87$ & $7 \cdot 08-8 \cdot 81$ \\
\hline & 11 & L1SP4 & $7 \cdot 67$ & $7 \cdot 85$ & $7 \cdot 06-8 \cdot 78$ \\
\hline & 12 & L1SP5 & $7 \cdot 93$ & $7 \cdot 83$ & $7 \cdot 05-8 \cdot 78$ \\
\hline & 13 & L2SP1 & $7 \cdot 19$ & $6 \cdot 70$ & $5 \cdot 93-7 \cdot 55$ \\
\hline & 14 & L2SP2 & $6 \cdot 31$ & $6 \cdot 62$ & $5 \cdot 88-7 \cdot 49$ \\
\hline & 15 & L2SP3 & $6 \cdot 82$ & $6 \cdot 58$ & $5 \cdot 87-7 \cdot 47$ \\
\hline & 16 & L2SP4 & $6 \cdot 46$ & $6 \cdot 65$ & $5 \cdot 88-7 \cdot 50$ \\
\hline & 17 & L2SP5 & $6 \cdot 16$ & $6 \cdot 69$ & $5 \cdot 94-7 \cdot 57$ \\
\hline & 18 & L3SP1 & $6 \cdot 18$ & $4 \cdot 41$ & $3 \cdot 75-5 \cdot 12$ \\
\hline & 19 & L3SP2 & $5 \cdot 24$ & $4 \cdot 36$ & $3 \cdot 73-5 \cdot 09$ \\
\hline & 20 & L3SP3 & $5 \cdot 45$ & $4 \cdot 33$ & $3 \cdot 73-5 \cdot 09$ \\
\hline & 21 & L3SP4 & $5 \cdot 22$ & $4 \cdot 42$ & $3 \cdot 79-5 \cdot 16$ \\
\hline & 22 & L3SP5 & $5 \cdot 25$ & $4 \cdot 53$ & $3 \cdot 89-5 \cdot 28$ \\
\hline \multirow[t]{11}{*}{$\mathrm{Hu}(2015)$} & 23 & $\mathrm{H} 7 \mathrm{C} 7$ & $10 \cdot 43$ & $10 \cdot 41$ & $9 \cdot 32-11 \cdot 65$ \\
\hline & 24 & $\mathrm{H} 7 \mathrm{C} 14$ & $11 \cdot 76$ & $10 \cdot 53$ & $9 \cdot 47-11 \cdot 80$ \\
\hline & 25 & $\mathrm{H} 7 \mathrm{C} 21$ & $13 \cdot 94$ & $10 \cdot 85$ & $9 \cdot 78-12 \cdot 17$ \\
\hline & 26 & $\mathrm{H} 5 \mathrm{CO}$ & $7 \cdot 69$ & $5 \cdot 47$ & $4 \cdot 68-6 \cdot 32$ \\
\hline & 27 & $\mathrm{H} 5 \mathrm{C} 7$ & $10 \cdot 05$ & $8 \cdot 19$ & $7 \cdot 28-9 \cdot 33$ \\
\hline & 28 & H5S13 & $7 \cdot 67$ & $8 \cdot 80$ & $7 \cdot 80-9 \cdot 95$ \\
\hline & 29 & $\mathrm{H} 5 \mathrm{C} 14$ & $10 \cdot 35$ & $8 \cdot 30$ & $7 \cdot 37-9 \cdot 46$ \\
\hline & 30 & $\mathrm{H} 5 \mathrm{C} 21$ & $9 \cdot 70$ & $8 \cdot 08$ & $7 \cdot 16-9 \cdot 23$ \\
\hline & 31 & $\mathrm{H} 3 \mathrm{C} 7$ & $6 \cdot 40$ & $5 \cdot 29$ & $4 \cdot 55-6 \cdot 14$ \\
\hline & 32 & $\mathrm{H} 3 \mathrm{C} 14$ & $5 \cdot 54$ & $5 \cdot 25$ & $4 \cdot 53-6 \cdot 12$ \\
\hline & 33 & $\mathrm{H} 3 \mathrm{C} 21$ & $4 \cdot 75$ & $5 \cdot 26$ & $4 \cdot 55-6 \cdot 14$ \\
\hline
\end{tabular}

Note: All tests were conducted in the beam or drum centrifuge at the University of Western Australia (UWA).

\section{CONCLUSIONS}

This paper has reported research in which the CEL approach was used to overcome the mesh distortion problem associated with numerical modelling of the penetration process of a spudcan into sand overlying clay. A modified Mohr-Coulomb model and Tresca model were used to describe the behaviour of the sand and clay, respectively. The numerical simulations show reasonable agreement with centrifuge tests on the dense and medium dense sand, illustrating that the softening behaviour of the sand and clay can be properly simulated numerically.

The predictions of the peak resistance from the experimental measurements and numerical simulations are within $15 \%$ of the predictions of the analytical model by $\mathrm{Hu}$ et al. (2014a), for loose to dense sands and various footing shapes (conical angle of 0 to $21^{\circ}$ ). The evolution of the friction angle shows that the sand around the advancing spudcan reached the critical state during deep penetration. The soil movement was replicated through the numerical simulation and the sand plug heights fit the ones from the centrifuge tests very closely. The sand plug height is stable and nearly constant for penetration greater than $0.5 \mathrm{D}$ below the sand-clay interface. Footing conical angle did not have a significant effect on the sand plug height.

An expression for the bearing capacity factor is proposed based on a large experimental and numerical database incorporating various footing shapes and soil conditions. To account for the scatter in the data, a simple statistical method was proposed to provide mean, upper and lower bounds for the penetration resistance in the clay layer.
The simplified prediction method of $\mathrm{Hu}$ et al. (2014b) is thus modified for estimating spudcan bearing capacity in sand overlying clay, which enables a simplified bearing capacity-depth profile to be constructed. The majority of the predictions of the punch-through distance based on the above method fall within $\pm 20 \%$ of those from comparable centrifuge tests.

\section{ACKNOWLEDGEMENTS}

This work forms part of the activities of the Centre for Offshore Foundation Systems (COFS), which is supported by the Lloyd's Register Foundation as a Centre of Excellence and now forms one of the primary nodes of the Australian Research Council (ARC) Centre of Excellence for Geotechnical Science and Engineering. Lloyd's Register Foundation invests in science, engineering and technology for public benefit, worldwide. This project has received additional support from the Australia-China Natural Gas Technological Partnership Fund and the ARC Discovery program. The authors are grateful for this support.

\footnotetext{
NOTATION

$D$ spudcan diameter

$d$ depth of penetration

$d_{\text {base }}$ depth of composite foundation from sand-clay interface $d_{\text {punch, test }}$ punch-through distance measured from centrifuge test

$H_{\mathrm{fdn}}$ height of composite foundation

$H_{\mathrm{s}}$ sand layer thickness
} 
$h_{\text {plug }}$ sand plug height

$I_{\mathrm{D}}$ relative density

$I_{\mathrm{R}}$ dilatancy index

$k$ strength gradient of clay

$N_{1,2}$ coefficient

$N_{\mathrm{c}}$ bearing capacity factor

$N_{\mathrm{c} 0} \quad$ value of $N_{\mathrm{c}}$ for smooth footing

$N_{\mathrm{c} \alpha} \quad$ contribution of normal stresses on cone face only

$p^{\prime} \quad$ mean effective stress

$q_{\text {clay }}$ bearing capacity in underlying clay

$q_{\text {peak }}$ peak resistance

$S_{\mathrm{t}}$ soil sensitivity

$s_{\mathrm{u}}$ remoulded undrained shear strength

$s_{\mathrm{u} 0}$ soil strength at lowest elevation of spudcan widest cross-sectional area

$s_{\mathrm{ui}}$ intact undrained shear strength of clay

$s_{\mathrm{um}}$ clay shear strength at sand-clay interface

$\alpha$ footing roughness factor

$\beta$ cone angle

$\gamma_{c}^{\prime}$ effective unit weight of clay

$\Delta \varepsilon_{1,2,3} \quad$ incremental principal plastic strain

$\Delta \xi \quad$ incremental plastic shear strain

$\delta_{\text {rem }}$ ratio of fully remoulded and intact shear strengths

$\kappa$ dimensionless strength increasing parameter for non-homogeneous cohesive soils

$\xi$ accumulated plastic shear strain

$\xi_{\mathrm{cv}}$ threshold plastic shear strain corresponding to $\phi_{\mathrm{cv}}$

$\xi_{\mathrm{p}}$ threshold plastic shear strain corresponding to $\phi_{\mathrm{p}}$

$\xi_{95}$ value of $\xi$ required for soil to undergo $95 \%$ remoulding

$\sigma$ standard deviation

$\sigma_{\mathrm{r}} \quad$ confining stress

$\phi \quad$ internal friction angle

$\phi_{\mathrm{cv}}$ constant volume friction angle of sand

$\phi_{\text {ini }}$ initial value of friction angle

$\phi_{\mathrm{p}}$ peak value of friction angle

$\psi$ dilation angle

$\psi_{\text {peak }}$ peak dilation angle

\section{REFERENCES}

Andersen, K. \& Schjetne, K. (2013). Database of friction angles of sand and consolidation characteristics of sand, silt, and clay. J. Geotech. Geoenviron. Engng 139, No. 7, 1140-1145.

Bolton, M. D. (1986). The strength and dilatancy of sands. Géotechnique 36, No. 1, 65-78, http://dx.doi.org/10.1680/ geot.1986.36.1.65.

Bolton, M. D. (1987). The strength and dilatancy of sands. Discussion. Géotechnique 37, No. 2, 219-226, http://dx.doi. org/10.1680/geot.1987.37.2.219.

Brennan, R., Diana, H., Stonor, R. W. P., Hoyle, M. J. R., Cheng, C. P., Martin, D. \& Roper, R. (2006). Installing jack-ups in punch-through-sensitive clays. Proceedings of the offshore technology conference, Houston, TX, USA, paper OTC 18268.

Brinch Hansen, J. (1970). A revised and extended formula for bearing capacity. Bull. Danish Geotech. Inst. 28, 5-11.

Cassidy, M. J. \& Houlsby, G. T. (1999). On the modelling of foundations for jack-up units on sand. Proceedings of the 31 st offshore technology conference, Houston, TX, USA, paper OTC 10995.

Cassidy, M. J. \& Houlsby, G. T. (2002). Vertical bearing capacity factors for conical footings on sand. Géotechnique 52, No. 9, 687-692, http://dx.doi.org/10.1680/geot.2002.52.9.687.

Dassault Systèmes (2011). ABAQUS analysis user's manual. Providence, RI, USA: Simulia Corp.

Dean, E. T. R. (2010). Offshore geotechnical engineering - principles and practice. London, UK: Thomas Telford.

Dounias, G. T., Potts, D. M. \& Vaughan, P. R. (1996). Analysis of progressive failure and cracking in old British dams. Géotechnique 46, No. 4, 621-640, http://dx.doi.org/10.1680/ geot.1996.46.4.621.

Einav, I. \& Randolph, M. F. (2005). Combining upper bound and strain path methods for evaluating penetration resistance. Int. J. Numer. Methods Engng 63, No. 14, 1991-2016.

Gan, C. T., Leung, C. F., Cassidy, M. J., Gaudin, C. \& Chow, Y. K. (2012). Effect of time on spudcan-footprint interaction in clay.
Géotechnique 62, No. 5, 401-413, http://dx.doi.org/10.1680/ geot.10.P.063.

Hanna, A. M. \& Meyerhof, G. G. (1980). Design charts for ultimate bearing capacity of foundations on sand overlying soft clay. Can. Geotech. J. 17, No. 2, 300-303.

Hossain, M. S., Randolph, M. F., Hu, Y. \& White, D. J. (2006). Cavity stability and bearing capacity of spudcan foundations on clay. Proceedings of the offshore technology conference, Houston, TX, USA, paper OTC 17770.

Houlsby, G. T. \& Martin, C. M. (2003). Undrained bearing capacity factors for conical footings on clay. Géotechnique 53, No. 5, 513-520, http://dx.doi.org/10.1680/geot.2003.53.5.513.

$\mathrm{Hu}, \mathrm{P}$. (2015). Predicting punch-through failure of a spudcan on sand overlying clay. $\mathrm{PhD}$ thesis, the University of Western Australia, Crawley, Australia.

Hu, P., Stanier, S. A., Cassidy, M. J. \& Wang, D. (2014a). Predicting peak resistance of spudcan penetrating sand overlying clay. J. Geotech. Geoenviron. Engng 140, No. 2, 04013009.

Hu, P., Wang, D., Cassidy, M. J. \& Stanier, S. A. (2014b). Predicting the resistance profile of a spudcan penetrating sand overlying clay. Can. Geotech. J. 51, No. 10, 1151-1164.

ISO (2012). ISO/FDIS 19905-1: Petroleum and natural gas industries - site-specific assessment of mobile offshore unit - part 1: jack-ups. Geneva, Switzerland: International Organization for Standardization.

Kostelnik, A., Guerra, M., Alford, J., Vazquez, J. \& Zhong, J. (2007). Jackup mobilization in hazardous soils. SPE Drilling and Completion 22, No. 1, 4-15.

Lacasse, S., Guttormsen, T., Nadim, F., Rahim, A. \& Lunne, T. (2007). Use of statistical methods for selecting design soil parameters. Proceedings of the 6th international offshore site investigation and geotechnics conference, London, UK, pp. $449-460$.

Lee, K. K. (2009). Investigation of potential spudcan punch-through failure on sand overlying clay soils. $\mathrm{PhD}$ thesis, University of Western Australia, Perth, Australia.

Lee, K. K., Cassidy, M. J. \& Randolph, M. F. (2013a). Bearing capacity on sand overlying clay soils: experimental and finite element investigation of potential punch-through failure. Géotechnique 63, No. 15, 1271-1284, http://dx.doi.org/10.1680/ geot.12.P.175.

Lee, K. K., Randolph, M. F. \& Cassidy, M. J. (2013b). Bearing capacity on sand overlying clay soils: a simplified conceptual model. Géotechnique 63, No. 15, 1285-1297, http://dx.doi.org/ 10.1680/geot.12.P.176.

McClelland, B., Young, A. G. \& Remmes, B. D. (1981). Avoiding jack-up rig foundation failure. Proceedings of the international symposium on geotechnical aspect of offshore and nearshore structures, Bangkok, Thailand, pp. 137-157.

Okamura, M., Takemura, J. \& Kimura, T. (1998). Bearing capacity predictions of sand overlying clay based on limit equilibrium methods. Soils Found. 38, No. 1, 181-194.

Osborne, J. J. \& Paisley, J. M. (2002). S E Asia jack-up punch-throughs: the way forward? Proceedings of conference on offshore site investigation and geotechnics - diversity and sustainability, pp. 301-306, London, UK: Society for Underwater Technology.

Osborne, J. J., Teh, K. L., Houlsby, G. T., Cassidy, M. J., Bienen, B. \& Leung, C. F. (2011). InSafeJIP: Improved guidelines for the prediction of geotechnical performance of spudcan foundations during installation and removal of jack-up units, joint industryfunded project, report no. EOG0574-Rev1. Woking, UK: RPS Energy.

Potts, D. M., Dounias, G. T. \& Vaughan, P. R. (1990). Finite element analysis of progressive failure of Carsington embankment. Géotechnique 40, No. 1, 79-101, http://dx.doi.org/10.1680/ geot.1990.40.1.79.

Potts, D. M., Kovacevic, N. \& Vaughan, P. R. (1997). Delayed collapse of cut slopes in stiff clay. Géotechnique 47, No. 5, 953-982, http://dx.doi.org/10.1680/geot.1997.47.5.953.

Pucker, T., Bienen, B. \& Henke, S. (2013). CPT based prediction of foundation penetration in siliceous sand. Appl. Ocean Res. 41, 9-18.

Qiu, G. \& Grabe, J. (2012). Numerical investigation of bearing capacity due to spudcan penetration in sand overlying clay. Can. Geotech. J. 49, No. 12, 1393-1407. 
Qiu, G. \& Henke, S. (2011). Controlled installation of spudcan foundations on loose sand overlying weak clay. Mar. Structs 24, No. 4, 528-550.

Randolph, M. F., Jamiolkowski, M. B. \& Zdravkovic, L. (2004). Load carrying capacity of foundations. In Proceedings of the Skempton memorial conference (eds R. J. Jardine, D. M. Potts and K. G. Higgins), vol. 1, pp. 207-240. London, UK: Thomas Telford.

SNAME (2008). Guidelines for site specific assessment of mobile jack-up units, T\&R Bulletin 5-5 and 5-5A, panes OC-7 site assessment of jack-up rigs. Jersey City, NJ, USA: Society of Naval Architects and Marine Engineers.

Teh, K. L. (2007). Punch-through of spudcan foundation in sand overlying clay. $\mathrm{PhD}$ thesis, National University of Singapore, Singapore.

Teh, K. L., Cassidy, M. J., Leung, C. F., Chow, Y. K., Randolph, M. F. \& Quah, M. (2008). Revealing the bearing capacity mechanisms of a penetrating spudcan through sand overlying clay. Géotechnique 58, No. 10, 793-804, http://dx.doi.org/10. 1680/geot.2008.58.10.793.
Teh, K. L., Leung, C. F., Chow, Y. K. \& Cassidy, M. J. (2010). Centrifuge model study of spudcan penetration in sand overlying clay. Géotechnique 60, No. 11, 825-842, http://dx.doi.org/10. 1680/geot.8.P.077.

Tho, K. K., Leung, C. F., Chow, Y. K. \& Swaddiwudhipong, S. (2012). Eulerian finite element technique for analysis of jack-up spudcan penetration. Int. J. Geomech. 12, No. 1, 64-73.

Troncone, A. (2005). Numerical analysis of a landslide in soils with strain-softening behaviour. Géotechnique 55, No. 8, 585-596, http://dx.doi.org/10.1680/geot.2005.55.8.585.

White, D. J., Teh, K. L., Leung, C. F. \& Chow, Y. K. (2008). A comparison of the bearing capacity of flat and conical circular foundations on sand. Géotechnique 58, No. 10, 781-792, http:// dx.doi.org/10.1680/geot.2008.3781.

Zhang, C. R., White, D. J. \& Randolph, M. F. (2011). Centrifuge modeling of the cyclic lateral response of a rigid pile in soft clay. J. Geotech. Geoenviron. Engng 137, No. 7, 717-729.

Zhou, H. \& Randolph, M. F. (2009). Numerical investigations into cycling of full-flow penetrometers in soft clay. Géotechnique 59, No. 10, 801-812, http://dx.doi.org/10.1680/geot.7.00200. 